\section{SHEA Luncheon at ICAAC}

SHEA will have its annual ICAAC luncheon on Tuesday, October 1 , 11:45 am to $1: 15 \mathrm{pm}$, in Rooms 8, 9, and 10 at the McCormick Center Hotel, Chicago, Illinois. The Hotel is directly across the street from the ICAAC convention site at McCormick Place.

The luncheon speaker will be Debra Nadzam, PhD, RN, Project

Manager, Clinical Indicator Development, Joint Commission on Accreditation of Healthcare Organizations.

All SHEA members and nonmembers are invited to attend. A reduced rate for the luncheon may be obtained by preregistering with SHEA headquarters at (609) 8451636.

\section{JCAHO Clinical Indicators Study}

The Joint Commission on Accreditation of Healthcare Organizations' (JCAHO) task force on Clinical Indicators has met to review the results of the testing of these indicators in the alpha test sites. These 13 sites have been testing eight clinical indicators as discussed by the task force chair, Dr. Robert Haley, in the October and November 1990 issues of the Newsletter. The task force has rated and ranked the importance of the various indicators. The JCAHO is now ready to embark on a two-year beta site testing of the revised indicators. Approximately 400 hospitals will be needed for the beta testing; 250 hospitals have volunteered already.

\title{
Healthcare Workers and HIV Debate Goes On
}

The issues of testing healthcare workers for human immunodeficiency virus (HIV) infection and work restrictions for HIV-infected healthcare workers continue to be hot topics of debate. The SHEA/APIC position paper dealing with these issues was published several months ago (1990;11(12):647-656.). Preliminary analysis of the HIV serosurvey of orthopedic surgeons undertaken during the annual meeting of the American Academy of Orthopaedic Surgeons in March 1991 was reported to show that, despite frequent occupational blood contact, including percutaneous injuries, there was no evidence of occupationally related HIV infection among the approximately 3,000 surgeons tested, including many who trained or practiced in areas of high HIV/acquired immunodeficiency syndrome (AIDS) incidence. In June, the American Medical Association debated and advised against mandatory screening of healthcare workers. Now, it is the public health services' turn; their recommendations, which were stuck in Foggy Bottom for several months, should be published as the Newsletter goes to press.

\section{Nuclear Medicine and Blood Risk}

You probably shook your head when you read the recent New England Journal of Medicine report (1990;332:1375.) about a mishap in which a patient was reinjected with someone else's blood during the performance of a nuclear medicine study. Unfortunately, the source of the erroneously injected blood was human immunodeficiency virus (HIV)-positive, and the recipient became infected with HIV despite prophylactic zidovudine therapy. Was this a rare, isolated event? Could it happen readily in your hospital? Similar instances of inadvertent blood mixup reportedly have occurred over the past few years during the performance of nuclear medicine studies in other hospitals. Now is a good time to review the safeguards used in your hospital to avoid blood mix-ups, and particularly the safeguards that are undertaken if blood specimens leave your hospital as part of the nuclear medicine procedure for radiolabeling. 


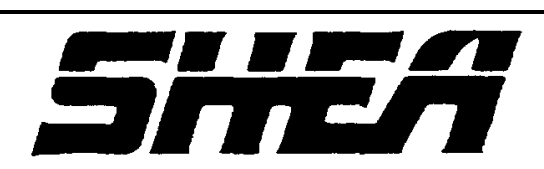

\section{Membership Application}

The Society for Hospital Epidemiology of America

Name

$\begin{array}{llll}\text { Degree } & \square \mathrm{MD} & \square \mathrm{PhD} & \mathrm{Cl} \text { Other }\end{array}$

Title (in hospital epidemiology)

Institution(s) name and address

\section{City}

Number of beds

Business telephone

Home address state

Category

$\square$ Non-Teaching

Fax

\section{Zip code}

Cl Teaching

City

state

Zip code

Home telephone

Indicate preferred address for membership directory

Home

Business

\section{Membership fees}

Non-US members please pay with draft for US dollars.

Cl Active membership—Calendar year dues: $\$ 85$

Applicants must hold a doctoral degree and should either be the head of a hospital epidemiology program or engaged on a full-time basis as a hospital epidemiologist, or employed by a federal, state, or local governmental health agency that has a direct interest in hospital epidemiology.

a Associate membership-Calendar year dues: $\$ 35$

Applicants must hold a doctoral degree and be participating in an appropriate training program in the field of hospital epidemiology. Proof of training must accompany this application.

Your membership fee includes a subscription to the Society's official journal, Infection Control and Hospital Epidemiology.

Please make checks payable to The Society for Hospital Epidemiology of America.

\section{Send application and remittance to: \\ SHEA Membership \\ 875 Kings Highway, Suite 200 \\ West Deptford, NJ 08096 \\ (609) 845-7220 \\ (609) 853-0411 FAX}

